Check for updates

Cite this: RSC Adv., 2017, 7, 41444

Received 27th June 2017

Accepted 21st August 2017

DOI: $10.1039 / \mathrm{c} 7 \mathrm{ra0} 124 \mathrm{~h}$

rsc.li/rsc-advances

\section{Effects of cationic surfactant on the bioaccumulation of polycyclic aromatic hydrocarbons in rice and the soil microbial community structure $\uparrow$}

\author{
Ni Ni, (D) ab Fang Wang, ${ }^{a}$ Yang Song, ${ }^{\star a}$ Renyong Shi, ${ }^{\text {ab }}$ Mingyun Jia, ${ }^{a}$ Yongrong Bian ${ }^{\mathrm{a}}$ \\ and Xin Jiang ${ }^{a}$
}

Cationic surfactants have been proposed as adsorbents for the remediation of aerobic agricultural soils contaminated with polycyclic aromatic hydrocarbons (PAHs). However, the effects of cationic surfactants on the bioavailability of PAHs in paddy soils and on the soil microbial community structure have not been investigated. In this study, cetyltrimethylammonium bromide (CTMAB) was added into an anaerobic $\mathrm{PAH}$-contaminated soil planted with rice (Oryza sativa L.). After harvest, the addition of $150 \mathrm{mg} \mathrm{kg}^{-1}$ CTMAB significantly reduced the bioavailability of PAHs in the soil and thus the bioaccumulation of PAHs from the soil into the rice roots. Based on the results of Tenax extraction, when applied at appropriate concentrations, CTMAB retarded the PAH desorption from the soil. The above effectiveness of CTMAB was better for high-molecular-weight PAHs (four to six benzene rings) than low-molecular-weight PAHs (two to three benzene rings). Amendment with CTMAB increased the bacterial diversity, species richness, and most of the bacterial phyla (especially involving Acidobacteria and Firmicutes) in the soils $(p<0.05)$. The contents of organic matter, ammonium nitrogen, and bioavailable PAH concentrations were the top three soil attributes that influenced the bacterial community structure in paddy soils amended with CTMAB. This study indicates that CTMAB applied at appropriate levels, can effectively reduce the environmental risk of $\mathrm{PAHs}$ in rice production, primarily via immobilization, and benefit the soil microbial ecology in the short term.

\section{Introduction}

Polycyclic aromatic hydrocarbons (PAHs) are a serious environmental concern due to their resistance to degradation and their potential toxicity and carcinogenicity to humans and many other organisms. ${ }^{\mathbf{1}, 2}$ PAHs have been detected in many farmland soils near industrial areas due to a wide range of anthropogenic sources, such as transportation emissions, sludge application, wastewater irrigation and incomplete combustion. ${ }^{3,4}$ The total $\mathrm{PAH}$ concentrations in agricultural soils in eastern China, varied extensively from 8.8 to $3880 \mu \mathrm{g} \mathrm{kg}{ }^{-1}$ in a collection of surface soil samples at 109 sites in a recent investigation. ${ }^{5}$ The available fraction of PAHs in soil can be taken up by food crops, thereby posing a potential risk to humans and other organisms. ${ }^{3}$ PAHs are transferred from contaminated soils into plants mainly via two pathways: root uptake from the soil solution ${ }^{6}$ and

${ }^{a}$ Key Laboratory of Soil Environment and Pollution Remediation, Institute of Soil Science, Chinese Academy of Sciences, Nanjing 210008, PR China. E-mail: ysong@ issas.ac.cn; Fax: +86 25 86881000; Tel: +862586881193

${ }^{b}$ University of the Chinese Academy of Sciences, Beijing 100049, PR China

$\dagger$ Electronic supplementary information (ESI) available. See DOI: 10.1039/c7ra07124h particle-phase deposition onto the waxy cuticle of plant leaves ${ }^{7}$ after volatilization into the air from the soil. Therefore, reducing the volatilization and bioavailability of PAHs will effectively reduce the PAH migration from soils into plants.

Cationic surfactants have been proposed as additive reagents in the remediation of soils contaminated with persistent organic pollutants (POPs). ${ }^{8-10}$ In a soil-water system containing cationic surfactant, the partitioning of PAHs into the soil organic matter (SOM) phase, the solubilization of PAHs into surfactant micelles in the aqueous phase at high surfactant concentrations, and the sorption of PAHs by the soil-sorbed surfactant are the three main mechanisms governing the fate of PAHs. ${ }^{11}$ When below the critical micelle concentration (CMC), cationic surfactants in monomer form can be sorbed by electronegative soils via ion exchange. ${ }^{\mathbf{1 1 2}}$ The tightly soilsorbed cationic surfactants facilitate the transport of solubilized PAHs to immobile sorbed surfactants, favouring the environmental remediation of PAHs at the localized scale. ${ }^{13}$ The mechanism of PAH adsorption on cationic surfactants is similar to the distribution role of SOM, and the distribution intensity of cationic surfactants is stronger than that of natural OM by 1030 times. $^{\mathbf{1 4}}$ Studies have reported that cetyltrimethyl 
ammonium bromide (CTMAB) and dodecylpyridinium bromide (DDPB) effectively inhibited the solid-vapor volatilization of PAHs and enhanced the soil retention of PAHs $(p<0.05)$ under aerobic conditions. ${ }^{15,16}$ Hexadecyltrimethylammonium (HDTMA) was successfully used in situ to enhance PAHs adsorption onto the aerobic soil to mitigate the PAH diffusion to the ground water and deep soil layer. ${ }^{17} \mathrm{Lu}$ and $\mathrm{Zhu}^{18}$ reported that concentrations of phenanthrene and pyrene in the chrysanthemum, cabbage, and lettuce were decreased with the increasing dose of CTMAB and DDPB after 30 days of growth $(p<0.05)$. Moreover, soil-use type (e.g., dry farming or paddy cultivation) can affect the environmental behaviour of PAHs in soils. ${ }^{19}$ However, to the best of our knowledge, whether amendment with cationic surfactants can reduce the bioavailability of PAHs in soils under anaerobic conditions remains unclear.

Cationic surfactants have not been applied broadly for soil remediation due to the unclear impact of the surfactants on soil microorganisms..$^{20}$ Reportedly, CTMAB and octadecyltrimethyl ammonium bromide (ODTMA) exerted toxicity on dehydrogenase activity in soil at concentrations exceeding $500 \mathrm{mg} \mathrm{kg}^{-1}$, whereas potential nitrification was inhibited by HDTMA and ODTMA at $50 \mathrm{mg} \mathrm{kg}{ }^{-1} .{ }^{21} \mathrm{Lu}$ and $\mathrm{Zhu}^{18}$ observed that amendments with CTMAB and DDPB had no significant impacts on the soil microbial biomass using the method of chloroform fumigation. Microbial community structure is often used as an indicator when monitoring soil quality and is affected by various environmental factors, such as moisture, nutrient availability and management practices. ${ }^{22}$ The assessment of microbial community composition within the soil ecosystem is helpful in determining whether the application of cationic surfactant is aggrading or degrading to soils. ${ }^{23}$ However, the effects of cationic surfactants on the microbial community structure in anaerobic farmland soils have not been reported.

Therefore, this study aimed to explore whether the cationic surfactant could reduce the mobility and bioavailability of PAHs in anaerobic soils with growing macrophytes. Meanwhile, the impacts of cationic surfactant on plant growth and the soil microbial community structure were investigated. CTMAB was selected and amended into a flooded farmland soil contaminated with PAHs. Pot experiments were conducted in a greenhouse using rice (Oryza sativa L.) as a typical macrophyte. Phospholipid fatty acid (PLFA) profiles were examined as reliable tracers of the effects of environmental stress on high-level taxonomic groups of soil microbes, and high-throughput sequencing of 16S rRNA genes was used to reveal the detailed structure of the soil bacterial community.

\section{Materials and methods}

\subsection{Chemical and soil preparation}

CTMAB of analytical grade was used without further treatment. The molecular formula of CTMAB is $\mathrm{C}_{19} \mathrm{H}_{42} \mathrm{BrN}$ with the molecular weight of 364.5 . The CMC of CTMAB is $360.8 \mathrm{mg} \mathrm{L}^{-1}$.

An agricultural soil contaminated with PAHs for more than 40 years was sampled from a depth of $0-20 \mathrm{~cm}$ in a region near a steel mill in a suburb of Nanjing, Jiangsu Province. The soil was air-dried and sieved through a $2 \mathrm{~mm}$ mesh. The soil had a pH of 7.4 and consisted of $27.60 \%$ sand, $63.52 \%$ silt, and $8.88 \%$ clay. The dissolved organic carbon (DOC) content of the soil was $309 \mathrm{mg} \mathrm{kg}^{-1}$, and the total nitrogen (N), phosphorus $(\mathrm{P})$, and potassium $(\mathrm{K})$ contents of the soil were $1.3,0.57$, and $17.4 \mathrm{~g} \mathrm{~kg}^{-1}$, respectively. The sum concentration of the 16 PAHs listed as priority pollutants by the United States Environmental Protection Agency (US EPA) in the soil sample is $7481 \pm 105 \mathrm{mg}$ $\mathrm{kg}^{-1}$ (Table S1 $\dagger$ ). The concentrations of 11 PAHs in the soil exceed the environmental quality standards for farmland soils in China (GB 15618-2008) by two orders of magnitude, respectively (Table S1†).

\subsection{Pot experiment}

Three kilogrammes of soil in each cylindrical polyvinyl chloride pot ( $20 \mathrm{~cm}$ in height and $20 \mathrm{~cm}$ in bottom diameter) was mixed with $3.82 \mathrm{~g}$ urea, $1.47 \mathrm{~g}$ potassium dihydrogen phosphate, $2.21 \mathrm{~g}$ potassium sulphate,,$^{24}$ then spiked with $1000 \mathrm{~mL}$ solution of CTMAB to obtain the concentration of CTMAB in the soil of $50 \mathrm{mg} \mathrm{kg}{ }^{-1}$ or $150 \mathrm{mg} \mathrm{kg}^{-1}$ (dry weight), and subsequently allowed to stand for $24 \mathrm{~h}$. Rice cultivar CyouII-513 is a middleseason indica hybrid rice. The rice seeds were disinfected in $10 \% \mathrm{H}_{2} \mathrm{O}_{2}$ solution for $30 \mathrm{~min}$, washed thoroughly with deionized water for $48 \mathrm{~h}$ and germinated in a clean salver with gauze for $36 \mathrm{~h}$. After germinating, every six unified seedlings were selected and transplanted into each pot immediately, when was the zero time of this experiment. Therefore, there were three treatments, i.e., Control, $50 \mathrm{CTMAB}$ and $150 \mathrm{CTMAB}$, each in triplicate. The rice was grown in a greenhouse under natural diurnal light conditions from May to October in 2015. Every 30 days, $10 \mathrm{~g}$ of soil mixed with rice roots from each pot was sampled using a soil borer and then freeze-dried. After freeze drying, the soil was separated from the roots via the electrostatic method $^{25}$ to measure the total and bioavailable concentrations of PAHs. The remaining soils sampled the last time were stored at $-80{ }^{\circ} \mathrm{C}$ until further analysis for determination of the PLFA profiles and high-throughput sequencing. After harvest, the rice samples were washed in deionized water and divided into grains, stems/leaves, and roots before weighing and determining the PAH concentrations.

\subsection{Desorption of PAHs in CTMAB-amended soil}

The impact of CTMAB on the desorption of PAHs from the ageing contaminated soils was determined. Briefly, $1 \mathrm{~g}$ of soil was spiked with $100 \mathrm{~mL}$ of deionized water or the given concentrations of CTMAB solution to obtain the concentrations of CTMAB in the soil of $0,50,100,200,400,600$, and $800 \mathrm{mg}$ $\mathrm{kg}^{-1}$. Mercuric chloride was added at $100 \mathrm{mg} \mathrm{L}^{-1}$ to prevent microbial degradation. Tenax beads $(0.25 \mathrm{~g})$ were then added to each flask, followed by shaking on a reciprocating shaker (HY-4, GuoHua, China) at $200 \mathrm{rpm}$ for $6 \mathrm{~h}$. After shaking, the Tenax beads were separated from the soil mixture using a glass separatory funnel, rinsed with $20 \mathrm{~mL}$ of deionized water 3 times, and then extracted in $15 \mathrm{~mL}$ of the hexane/acetone solution $(1: 1, \mathrm{v} / \mathrm{v})$ with ultrasonication for $5 \mathrm{~min}$ three times. The combined extracts were cleaned with silica gel, concentrated to 
$1 \mathrm{~mL}$ and then analysed by gas chromatography-mass spectrometry (GC-MS, Agilent 7890A/5975C, Santa Clara, CA).

\subsection{PAHs extraction and quantification in soil and rice}

Total PAHs in soils/rice were extracted by accelerated solvent extraction (ASE 200, Dionex, Sunnyvale, CA, USA). ${ }^{26}$ Briefly, $1 \mathrm{~g}$ of soil or $0.5 \mathrm{~g}$ of rice sample was homogenized with $5 \mathrm{~g}$ of diatomaceous earth, respectively, and extracted using hexane/ acetone $(4: 1, \mathrm{v} / \mathrm{v})$ at $100{ }^{\circ} \mathrm{C}$ and $1500 \mathrm{psi}$. The extracts were rotary evaporated at $50{ }^{\circ} \mathrm{C}$ to $1 \mathrm{~mL}$. The concentrated samples were passed through the silica gel/anhydrous sodium sulfate column for soil samples and the sulfonated silica/anhydrous sodium sulfate column for rice samples, respectively, eluting with $15 \mathrm{~mL}$ of hexane/dichloromethane $(9: 1, \mathrm{v} / \mathrm{v})$. The eluate was concentrated to $1 \mathrm{~mL}$ for the detection of PAHs by GC-MS.

The concentrations of bioavailable PAHs in soil were extracted using hydroxypropyl- $\beta$-cyclodextrin (HPCD). ${ }^{27}$ Briefly, $1 \mathrm{~g}$ of freeze-dried soil was extracted with $20 \mathrm{~mL}$ of HPCD $\left(50 \mathrm{mmol} \mathrm{L}^{-1}\right)$ in a glass centrifuge tube by shaking on an orbital shaker at $200 \mathrm{rpm}$ for $20 \mathrm{~h}$ followed by centrifugation for $30 \mathrm{~min}$. The supernatant was discarded, and the soil residue was shaken with deionized water for $10 \mathrm{~min}$ and then centrifuged again. This supernatant was also discarded. Then, the total PAH concentrations in the soil residue were measured using the method described above. The bioavailable PAH concentration in the soil was calculated by subtracting the total PAH concentration in the soil residue after HPCD extraction from the total PAH concentration in the soil before HPCD extraction.

\subsection{High-throughput sequencing}

The soils with growing rice collected after harvest were subjected to high-throughput sequencing analysis. The genomic DNA in the samples was extracted using the PowerSoil DNA Isolation Kit (MO BIO Laboratories Inc., Carlsbad, USA). The DNA concentration was measured on a NanoDrop 2000C ultramicrospectrophotometer (Thermo Scientific, Waltham, USA), and the quality was assessed using $0.8 \%$ agarose gel electrophoresis. The V3-V4 region of bacterial 16S rRNA was amplified by PCR for high-throughput pyrosequencing using the universal primers $338 \mathrm{~F}$ ( $5^{\prime}$-ACTCCTACGGGAGGCAGCA- $3^{\prime}$ ) and 806R ( $5^{\prime}$-GGACTACHVGGGTWTCTAAT- $\left.3^{\prime}\right)$. The PCR programme was as follows: $95{ }^{\circ} \mathrm{C}$ for $3 \mathrm{~min}$ and 27 cycles of $95{ }^{\circ} \mathrm{C}$ for $30 \mathrm{~s}, 55^{\circ} \mathrm{C}$ for $30 \mathrm{~s}$, and $72{ }^{\circ} \mathrm{C}$ for $45 \mathrm{~s}$, with a final extension at $72{ }^{\circ} \mathrm{C}$ for $10 \mathrm{~min}$. The amplicons were determined using the Illumina MiSeq PE300 sequencing platform (Illumina, Inc., CA, USA) according to the manufacturer's recommendations. The raw sequencing data were deposited in the SRA database of NCBI under the study accession number SRP109311.

The barcoded 16S RNA gene sequences were trimmed into libraries using the quantitative insights into microbial ecology (QIIME) program version 1.8.0. ${ }^{28}$ To retain only high-quality sequences for the downstream analysis, sequences that were less than $100 \mathrm{bp}$ in length after quality trimming, contained one or more ambiguous base-calls (N), or had $<90 \%$ quality scores $>$ Q20 were eliminated. High-quality sequences were clustered into operational taxonomical units (OTUs) at a $97 \%$ similarity level using UPARSE version 7.1. ${ }^{29}$ The phylogenetic affiliation of each 16S rRNA gene sequence was analysed using RDP Classifier (http://rdp.cme.msu.edu/) against the Silva (SSU117) 16S rRNA database using a confidence threshold of $70 \%{ }^{30}$ The Shannon index representing $\alpha$-diversity was calculated in MOTHUR v.1.30.1. ${ }^{31}$ Canonical correspondence analysis (CCA) was performed using the Vegan ecological function package in $\mathrm{R}$ with the high-throughput sequencing for 16S rDNA genes to compare the bacterial community structures among the control and CTMAB-amended treatments, as well as to reveal the relationship between species abundance and environmental variables, such as soil pH, DOC, OM, cation exchange capacity (CEC), nitrate nitrogen $\left(\mathrm{NO}_{3}{ }^{-}-\mathrm{N}\right)$ and ammonium nitrogen $\left(\mathrm{NH}_{4}{ }^{+}-\mathrm{N}\right)$.

\subsection{Quality control and statistical analysis}

The recovery of the 16 PAHs was determined as a measure of quality control. Briefly, $10 \mathrm{~g}$ of soil were spiked with the mixed standard samples of the 16 PAHs $\left(500 \mu \mathrm{g} \mathrm{kg}^{-1}\right)$. The soil samples were extracted and purified using the procedure described above. To estimate the recoveries of the PAH residues in rice, $0.5 \mathrm{~g}$ of freeze-dried rice root, stem and leaves, or grain samples was spiked with the mixed standard samples of the 16 PAHs $\left(500 \mu \mathrm{g} \mathrm{kg}{ }^{-1}\right)$. The sample was extracted and analysed using the same procedures described above. The average recoveries of triplicate samples were $96 \% \pm 7 \%$ for the soil sample and $105 \pm 3 \%$ for the rice sample. Data were statistically analysed using analysis of variance (ANOVA) and least significant difference (LSD) post hoc comparison tests with SPSS V14.0 (SPSS Inc., Chicago, IL, USA) at a $p<0.05$ significance level.

\section{Results and discussions}

\subsection{Rice biomass and uptake of PAHs}

The impact of CTMAB on the growth of rice is presented in Fig. S1. $\dagger$ After 150 days, the amendment with 50 or $150 \mathrm{mg} \mathrm{kg}^{-1}$ CTMAB did not cause the rice to curl, yellow or die. Compared to the control, the biomass of rice shoots and roots were not significantly affected $(p<0.05)$. CTMAB was reported to provide a certain amount of $\mathrm{N}$ for plant growth as an alkyl-substituted ammonium salt. ${ }^{32}$ In the present study, the content of $\mathrm{NH}_{4}{ }^{+}-$ $\mathrm{N}$ in the 150 CTMAB treatment was significantly increased compared with that in the other treatments (Table S2 $\dagger$ ), however, $150 \mathrm{mg} \mathrm{kg}^{-1}$ CTMAB did not significantly promote the rice yield $(p<0.05)$.

The PAH concentrations in rice stem, leaf, grain and root are presented in Fig. S2. $\dagger$ The PAH concentrations in rice roots were significantly higher than those in the shoot. The rice root-toshoot translocation factor was less than 0.13 (Table S3†). Thus, PAHs were preferentially bioaccumulated in the roots of rice. No differences in the PAH concentrations in rice shoots among all treatments or in the rice roots between the control and 50 CTMAB treatments were observed. However, compared to the control, the PAH concentration in the rice roots in the 150 CTMAB treatment was decreased by $16 \% \pm 2 \%$. The 
bioconcentration factor of the PAHs in rice roots in the 150 CTMAB treatment was also significantly lower than that in the control (Table S3†). These results indicate that the amendment with $150 \mathrm{mg} \mathrm{kg}{ }^{-1}$ CTMAB can reduce the translation of PAHs from the soil to rice roots, where PAHs preferentially bioaccumulate. After 150 days, compared to the control, the reductions in 2(+3)-ring, 4-ring, and 5(+6)-ring PAHs bioaccumulated in the rice roots in the $150 \mathrm{CTMAB}$ treatment varied greatly, with the reductions of $10 \% \pm 2 \%, 23 \% \pm 8 \%$, $20 \% \pm 4 \%$, respectively (Fig. 1). This result indicates that CTMAB applied at appropriate levels, was better at reducing the translation of high-molecular-weight (HMW) PAHs to rice roots than that of low-molecular-weight (LMW) PAHs, potentially because PAHs with a higher $K_{\mathrm{ow}}$ have a greater tendency to participate in the soil and CTMAB-amended soil. ${ }^{11,33}$ Therefore, the bioaccumulation of HMW PAHs in rice was more substantially reduced by the addition of CTMAB. From the perspective of crop safety, HMW PAHs are of greater concern because they are more carcinogenic than LMW PAHs. ${ }^{34}$ Therefore, reducing the bioaccumulation of HMW PAHs in rice would effectively decrease the health hazard attributed to HMW PAHs.

\subsection{PAH concentrations in soils with growing rice}

The dissipation of the 16 PAHs in the soils is shown in Fig. S3. $\dagger$ The total concentration of $\sum 16$ PAHs, 2(+3)-ring, 4-ring, and $5(+6)$-ring PAHs in the control decreased during the period $(p<0.05)$. After 150 days, no significant differences in the PAH residues were observed between the control and 50 CTMAB treatments, while the addition of $150 \mathrm{mg} \mathrm{kg}{ }^{-1}$ CTMAB significantly suppressed the dissipation of either HMW or LMW PAHs. The percentages of the HPCD-extracted concentrations in the total concentrations were calculated to express the bioavailability of the PAHs in the soil (Fig. 2). After 150 days, the percentage of the HPCD-extracted concentrations in the total

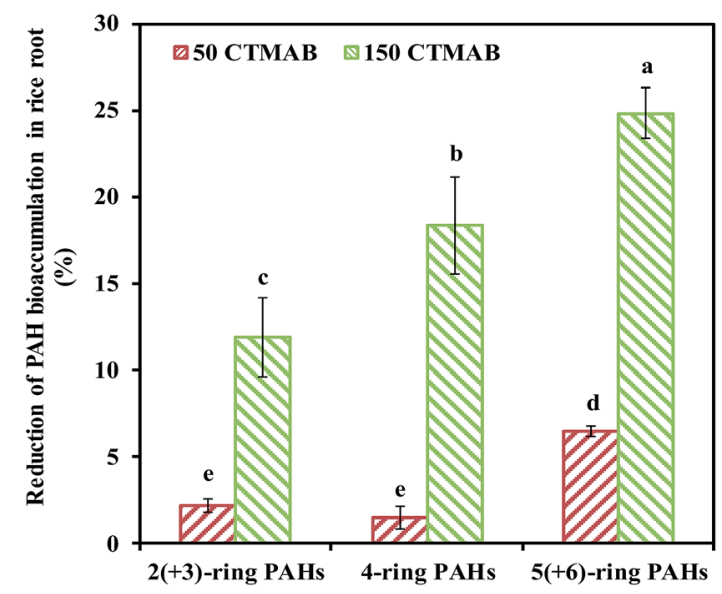

Fig. 1 Reduction in PAH bioaccumulation in rice roots grown in soils amended with/without cetyltrimethylammonium bromide (CTMAB) grouped according to the number of rings in the $\mathrm{PAH}$ structure. 50 CTMAB: $50 \mathrm{mg} \mathrm{kg}{ }^{-1}$ CTMAB addition; 150 CTMAB: $150 \mathrm{mg} \mathrm{kg}^{-1}$ $C T M A B$ addition. Different letters indicate significant differences among the treatments based on LSD post hoc comparison tests at $p<$ 0.05. Error bars indicate the standard deviation $(N=3)$. concentrations of $\sum 16$ PAHs, 2(+3)-ring, 4-ring, and 5(+6)-ring PAHs in the 150 CTMAB treatment was significantly lower than that in the control or 50 CTMAB treatments, which could be ascribed to the higher residues (Fig. $\mathrm{S} 3 \dagger$ ) and the lower HPCDextractable PAHs (Fig. S4†) in CTMAB-amended soils than in the control. Additionally, after 150 days, the dissipations of $\sum 16$ PAHs in the control, $50 \mathrm{CTMAB}$, and $150 \mathrm{CTMAB}$ treatments were limited, with the extents of $23 \% \pm 3 \%, 24 \% \pm 3 \%$, and $16 \% \pm 5 \%$, respectively (Fig. S3†). The results suggest that $150 \mathrm{mg} \mathrm{kg}{ }^{-1}$ CTMAB can reduce the bioavailability of PAHs primarily via immobilization rather than biodegradation under anaerobic conditions. As shown in Fig. S5, $\uparrow$ the bioavailable concentrations of $\sum 16$ PAHs, 2(+3)-ring, 4-ring, and 5(+6)-ring PAHs in the soils were well correlated with the PAH concentrations in rice roots $\left(R^{2}=0.58-0.85, p<0.05\right)$, indicating that the amendments with CTMAB reduced PAH bioaccumulation in rice roots mainly by decreasing the bioavailability of PAHs in the anaerobic soils. External $\mathrm{OM}$ such as humic acid and cationic surfactants were reported to increase the SOM content and then reduce the release and availability of hydrophobic pesticides from soils. ${ }^{12}$ In this study, the sorption of PAHs to the soil amended with CTMAB affected the distribution of PAHs in soil particles and solution, which was likely the main reason for the reduction of the $\mathrm{PAH}$ uptake by rice. Additionally, $150 \mathrm{mg}$ $\mathrm{kg}^{-1}$ CTMAB was more effective at immobilizing HMW PAHs than LMW PAHs in the soils $(p<0.05)$. Wei et al. ${ }^{11}$ also found that the sorption intensity of PAHs onto the soil-sorbed surfactant was positively related to the $K_{\text {ow }}$ of the PAHs, that is, LMW PAHs, which are highly soluble in water, ${ }^{35}$ are more poorly retained by the cationic surfactant-amended soils.

\subsection{Desorption of PAHs by CTMAB}

To further demonstrate the soil-retention enhancement of PAHs by CTMAB, desorption experiments were carried out in the soil-solution system. The bioavailability of contaminants in soil is controlled by their desorption rates from the soils. The fraction of PAHs that rapidly desorbs from soil, as measured by the $6 \mathrm{~h}$ extraction using Tenax, is considered the bioavailable fraction. ${ }^{36}$ The effect of cationic surfactants on the desorption of PAHs from the aged contaminated soil is shown in Fig. 3. The addition of cationic surfactants significantly retarded the desorption of PAHs $(p<0.05)$. The desorption percentage of HMW PAHs sharply decreased after the application of $100 \mathrm{mg}$ $\mathrm{kg}^{-1}$ CTMAB and then remained almost unchanged as the CTMAB concentration further increased (200-400 $\mathrm{mg} \mathrm{kg}^{-1}$ ). At low levels of sorbed cationic surfactant, the surfactant sorbed by the soil/minerals adsorbs contaminants via the cation-exchange processes. At high surfactant levels, the sorbed surfactant behaves essentially as a partition phase via London attractive forces, and the sorption coefficient becomes less dependent on the surfactant loading. ${ }^{11,37,38}$ LMW PAHs had a similar desorption behaviour as HMW PAHs, however, the desorption percentage stabilized at a higher CTMAB content (400 $\mathrm{mg} \mathrm{kg}^{-1}$ ). This is consistent with the result of the pot experiment, leading to that CTMAB was better at reducing the bioaccumulation of HMW PAHs than LMW PAHs in rice roots (Fig. 1). 

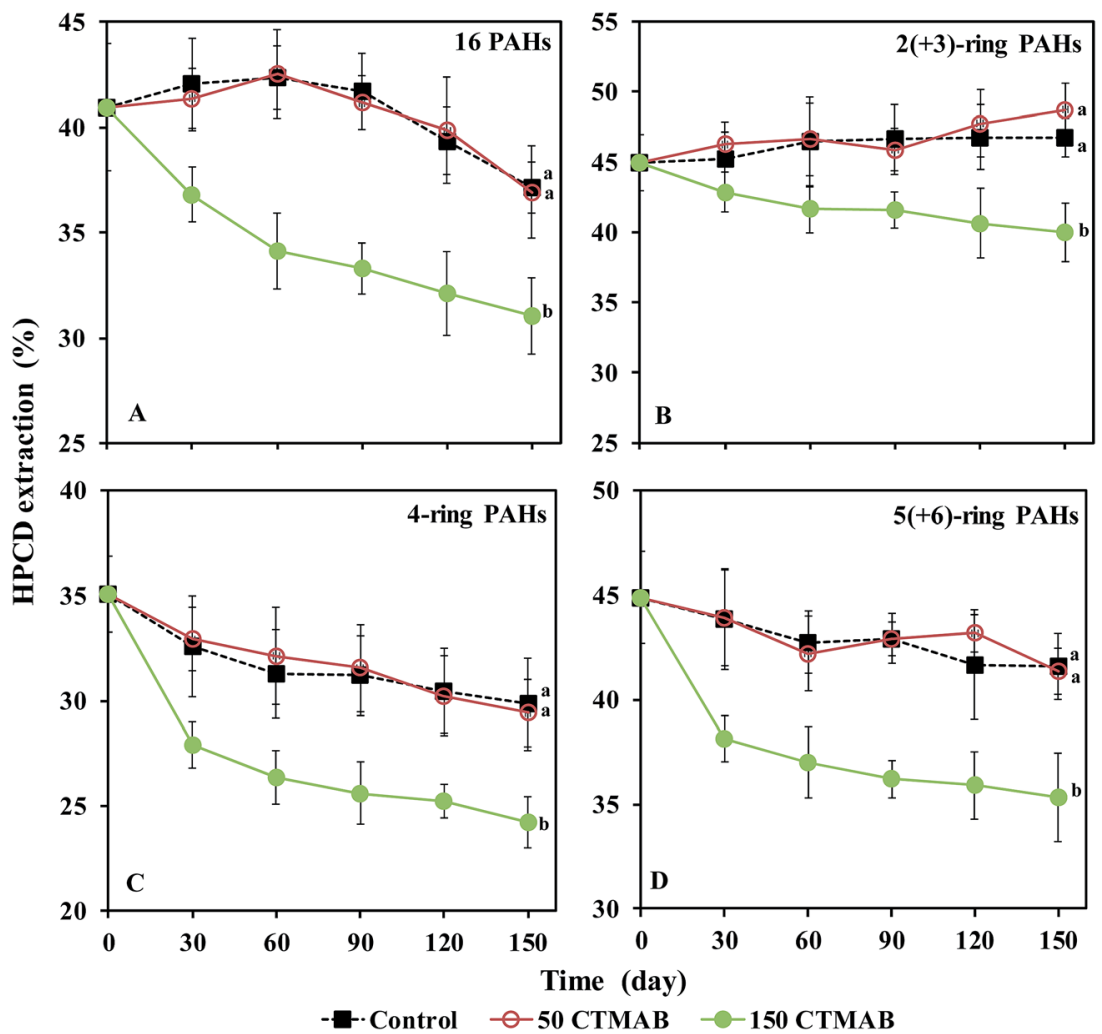

Fig. 2 Time course of the percentage of HPCD-extracted PAHs in the total concentrations of $\sum 16$ PAHs (A), 2(+3)-ring (B), 4-ring (C), and 5(+6)ring (D) PAHs in the soils after 150 days of rice growth. Control: no cetyltrimethylammonium bromide (CTMAB) addition; 50 CTMAB: 50 mg kg ${ }^{-1}$ CTMAB addition; 150 CTMAB: $150 \mathrm{mg} \mathrm{kg}^{-1}$ CTMAB addition. Different letters indicate significant differences among the treatments based on LSD post hoc comparison tests at $p<0.05$. Error bars indicate the standard deviation $(N=3)$.

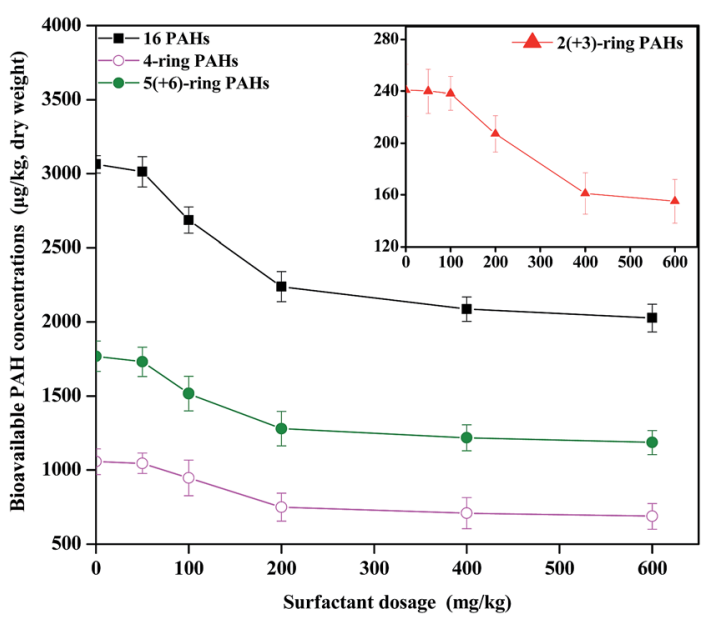

Fig. 3 Bioavailable concentration of $\sum 16 \mathrm{PAHs}, 2(+3)$-ring, 4-ring, and $5(+6)$-ring PAHs in the soil in the presence of varying concentrations of cetyltrimethylammonium bromide (CTMAB) with Tenax extraction. Error bars indicate the standard deviation $(N=3)$

\subsection{Soil bacterial community structure}

3.4.1 Bio-indicators of soil ecosystem. Soil contains a myriad of bacteria, of which the community structure is crucial to the soil functional stability. ${ }^{39}$ To evaluate bacterial community structures in the soils after CTMAB application, high-throughput sequencing of the soils from the control, 50 CTMAB, and 150 CTMAB treatments was conducted. The addition of CTMAB reduced the bioavailability of PAHs, which may mitigate the toxicity of PAHs to bacteria. Then, as shown in Fig. S6, $\uparrow$ the bacterial diversities (as expressed by the Shannon index) were increased in the CTMAB-amended treatments with lower PAH bioavailability (Fig. 2), although without significant extents. Nutrient efficiency and biodegradation of POPs in soil could be promoted by a diverse microbial community structure. ${ }^{39,40}$ Amendment with CTMAB significantly increased the species richness index (Fig. S6 $\dagger$ ). The bacterial richness index is one of bio-indicator of soil ecosystem restoration. ${ }^{\mathbf{4 1}}$ Additionally, the fungal biomass in the anaerobic soils was increased by CTMAB amendment ( $p>0.05$, data not shown here). Fungi played an important role in improving nutrient cycling and soil physical structure. ${ }^{42}$

3.4.2 Abundances of bacterial phyla. Changes in the structure of soil bacterial communities may offer a key to understanding the impact of environmental factors on soil quality in agriculturally managed systems. ${ }^{43}$ The composition of the soil bacterial phyla is shown in Fig. 4. After 150 days, the amendment of CTMAB had no significant effect on the dominant members of bacterial community structure. Eleven phyla had relative abundances greater than $1 \%$ in each treatment, and these phyla accounted for 95-96\% of the total bacterial abundances. Among the top 11 bacterial phyla, compared to the 

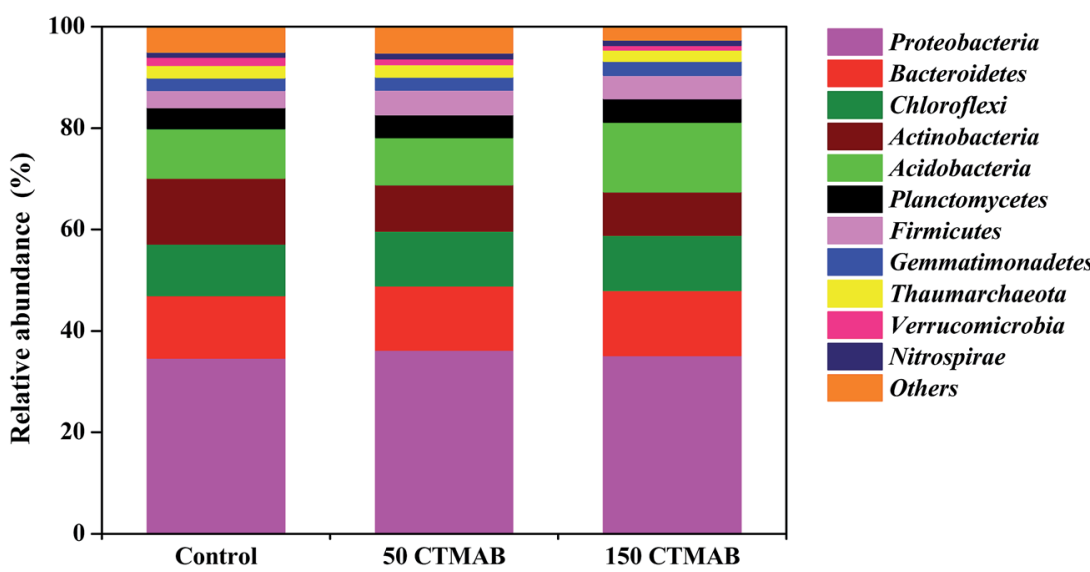

Fig. 4 Composition of bacterial phyla in the soils after 150 days of rice growth. Control: no cetyltrimethylammonium bromide (CTMAB) addition; 50 CTMAB: $50 \mathrm{mg} \mathrm{kg}^{-1}$ CTMAB addition; 150 CTMAB: $150 \mathrm{mg} \mathrm{kg}^{-1}$ CTMAB addition.

control, the relative abundances of Actinobacteria, Thaumarchaeota and Verrucomicrobia in the CTMAB-amended soils decreased by $29-34 \%, 3-10 \%$ and $26-40 \%$, while other 8 phyla, i.e. Proteobacteria, Bacteroidetes, Chloroflexi, Acidobacteria, Planctomycetes, Firmicutes, Gemmatimonadetes, Nitrospirae, all increased, respectively by $1-5 \%, 2-9 \%, 11-14 \%, 0.5-40 \%$, $11-12 \%, 21-42 \%, 3-9 \%$, and $2-18 \%$. In the CTMAB-amended treatments, the relative abundances of most of the phyla increased (positive data in Fig. S7†), while those of a small part of the phyla decreased (negative data in Fig. S7 $\dagger$ ) among all of the 42 phyla. Moreover, the relative abundances of some phyla, including Chloroflexi and Nitrospirae which were reported to be more sensitive to PAH toxicity, ${ }^{44}$ increased in the CTMABamended treatments with lower PAH bioavailability (Fig. 2).

After $150 \mathrm{mg} \mathrm{kg}{ }^{-1}$ CTMAB application, the significant changes occurred in the relative abundance of four phyla (Fig. 4 and $\mathrm{S} 7 \dagger$ ), i.e. Actinobacteria, Verrucomicrobia, Acidobacteria and Firmicutes, indicating that members of these phyla are more responsive to CTMAB amendments. Actinobacteria and Verrucomicrobia were both common in PAH-contaminated soils, ${ }^{45,46}$ and were capable to grow on PAHs if other carbon and energy source was available. ${ }^{47} \mathrm{~A}$ high reduction in their relative abundances in the CTMAB-amended soils indicates that the strong immobilization process of PAHs on CTMAB likely made PAHs not very readily accessible for the associated strains, although the hydrocarbons were not essential for growth. ${ }^{47}$ Acidobacteria and Firmicutes were also found in PAH-contaminated environments worldwide and include several hydrocarbon-degrading species. ${ }^{48}$ It was reported that the variables of $\mathrm{pH}$ and DOC were significantly positively correlated with Acidobacteria in the surface sediment. ${ }^{49}$ Firmicutes showed proximity with some ammonium dependent bacteria, ${ }^{50}$ and TOC was positively correlated with the abundance of Firmicutes. ${ }^{51}$ In the resent study, the amendment of CTMAB increased the soil pH, DOC, TOC and $\mathrm{NH}_{4}{ }^{+}-\mathrm{N}$ (Table $\mathrm{S} 2 \uparrow$ ), and simultaneously increased the relative abundances of these two bacterial phyla (Fig. 4 and S7 $\uparrow$ ). Acidobacteria and Firmicutes are also reported to have an infinite number of beneficial characteristics for soil ecology. ${ }^{52}$ In summary, the application of CTMAB at appropriate levels had a limited effect on the changes in the main members of bacterial phyla, promoted the abundances of most bacteria phyla, and benefit the soil microbial ecology in the short term.

3.4.3 Environmental factors affecting bacterial community. The relationship between the bacterial community structure and environmental variables in the paddy soil was estimated via CCA using the high-throughput sequencing data obtained from the soils after 150 days of rice growth (Fig. 5). The bacterial community composition in the 50 CTMAB treatment was similar to that in the control, while $150 \mathrm{mg} \mathrm{kg}^{-1}$ СТMAB significantly changed the soil bacterial community composition. Among the soil physiochemical properties and bioavailable PAH concentrations, the contents of $\mathrm{OM}, \mathrm{NH}_{4}{ }^{+}-\mathrm{N}$ and bioavailable $\sum 16$ PAHs were the top three soil attributes that influenced the bacterial community structure in the paddy soil.

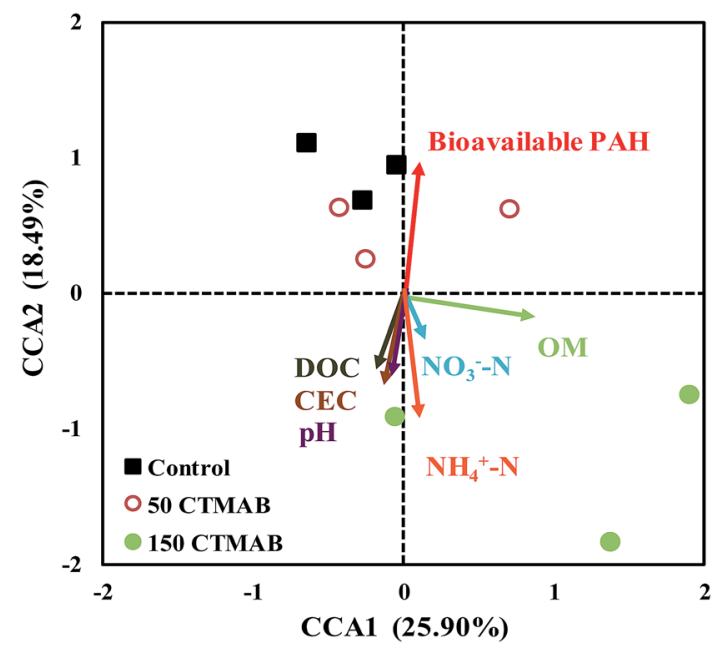

Fig. 5 Canonical correspondence analysis (CCA) of the bacterial community and environmental variables, i.e., $\mathrm{pH}$, cation exchange capacity (CEC), organic matter (OM), dissolved organic carbon (DOC), nitrate nitrogen $\left(\mathrm{NO}_{3}{ }^{-}-\mathrm{N}\right)$, ammonium nitrogen $\left(\mathrm{NH}_{4}{ }^{+}-\mathrm{N}\right)$, and bioavailable concentrations of $\sum 16 \mathrm{PAHs}$ in soils amended with/ without cetyltrimethylammonium bromide (CTMAB) after 150 days of rice growth. 
SOM was observed to improve the bacterial biomass, diversity, and community structure in forest and agricultural soils after fertilizer application. ${ }^{\mathbf{4 4 5 3}}$ Kennedy et al. $^{\mathbf{5 4}}$ discovered that the soil $\mathrm{N}$ status was more important controller of the bacterial community structure than plant rhizosphere effects. The bacterial 16S rRNA gene copies significantly correlated with the soil $\mathrm{NH}_{4}{ }^{+}-\mathrm{N}$ contents. ${ }^{55}$ The decreased bioavailable concentrations of $\sum 16$ PAHs would reduce their toxicity to bacterial and then affect bacterial community compositions. ${ }^{44}$ In this study, in the 150 CTMAB treatment, the content of $\mathrm{NH}_{4}{ }^{+}-\mathrm{N}$ was significantly increased (Table S2 $\dagger$ ), and the bioavailable PAH concentrations were markedly decreased (Fig. 2 and S4 $\dagger$ ). Thus, the bacterial community structure was jointly affected by the changes in the bioavailability of PAHs and the soil physiochemical properties both caused by CTMAB application.

\section{Conclusion}

CTMAB, applied at appropriate levels, can effectively enhance the sorption of PAHs onto soils and retard the PAH desorption from soils, thereby reducing the transfer of PAHs from paddy soils to rice. The bacterial diversity and species richness in the CTMAB-amended soils were increased in varying degrees, as well as the relative abundances of most bacterial phyla. The changes in the bioavailability of PAHs and the soil physiochemical properties caused by CTMAB application jointly affected the bacterial community structure. Future research monitoring the long-term effects of CTMAB on the PAH bioavailability and the bacterial community structure during paddy cultivation is necessary to further verify the safe use of CTMAB in anaerobic soils.

\section{Conflicts of interest}

There are no conflicts of interest to declare.

\section{Acknowledgements}

This study was supported by the National Key Basic Research Program of China (2014CB441105); Key Program of Frontier Sciences, Chinese Academy of Sciences (QYZDJ-SSW-DQC035); National Science and Technology Major Project of China (2016YFD08000204); the National Natural Science Foundation of China (41671236); the "135" Plan and Frontiers Program of the Institute of Soil Science, Chinese Academy of Sciences (ISSASIP1614); and the Outstanding Youth Fund of Natural Science Foundation of Jiangsu, China (BK20150050).

\section{References}

1 Y. B. Man, Y. Kang, H. S. Wang, W. Lau, H. Li, X. L. Sun, J. P. Giesy, K. L. Chow and M. H. Wong, J. Hazard. Mater., 2013, 261, 770-776.

2 C. H. Gong, G. Shen, H. O. Huang, P. R. He, Z. G. Zhang and B. Q. Ma, Chemosphere, 2017, 168, 58-64.

3 M. Usman, K. Hanna and S. Haderlein, Sci. Total Environ., 2016, 569, 179-190.
4 Y. Z. Gao, X. J. Hu, Z. Y. Zhou, W. Zhang, Y. Z. Wang and B. Q. Sun, Environ. Pollut., 2017, 222, 465-476.

5 Z. Sun, J. Liu, S. J. Zhuo, Y. C. Chen, Y. Y. Zhang, H. Z. Shen, X. Yun, G. F. Shen, W. P. Liu, E. Y. Zeng and S. Tao, Environ. Sci. Pollut. Res., 2017, 24, 12168-12175.

6 S. Namiki, T. Otani and N. Seike, Soil Sci. Plant Nutr., 2013, 59, 669-679.

7 M. Odabasi, E. O. Falay, G. Tuna, H. Altiok, M. Kara, Y. Dumanoglu, A. Bayram, D. Tolunay and T. Elbir, Environ. Sci. Technol., 2015, 49, 2105-2114.

8 S. A. Boyd, J. F. Lee and M. M. Mortland, Nature, 1988, 333, 345-347.

9 L. Z. Zhu, L. Lu and D. Zhang, Front. Environ. Sci. Eng. China, 2010, 4, 373-386.

10 M. J. Garcia-Galan, M. Sordet, A. Buleté, J. Garric and E. Vulliet, Sci. Total Environ., 2017, 592, 554-564.

11 J. Wei, G. H. Huang, J. Li and X. J. Wang, Ind. Eng. Chem. Res., 2016, 55, 4811-4819.

12 M. C. Hernández-Soriano, A. Peña and M. D. Mingorance, Sci. Total Environ., 2007, 378, 109-113.

13 S. Simpanen, R. Makela, J. Mikola, H. Silvennoinen and M. Romantschuk, Int. Biodeterior. Biodegrad., 2016, 106, 117-126.

14 M. O. Boulakradeche, D. E. Akretche, C. Cameselle and N. Hamidi, Electrochim. Acta, 2015, 174, 1057-1066.

15 L. Lu and L. Z. Zhu, Environ. Sci. Pollut. Res., 2012, 19, 15151523.

16 X. J. Liang, C. L. Guo, C. J. Liao, S. S. Liu, L. Y. Wick, D. Peng, X. Y. Yi, G. N. Lu, H. Yin, Z. Lin and Z. Dang, Environ. Pollut., 2017, 225, 129-140.

17 W. J. Geliner, X. D. Zhao, M. Girand, S. A. Boyd and T. C. Voice, J. Environ. Eng., 2006, 132, 1659-1663.

18 L. Lu and L. Z. Zhu, Environ. Pollut., 2009, 157, 1794-1799.

19 S. Shankar, Management and Remediation of Problem Soils, Solid Waste and Soil Pollution, Springer, Singapore, 2017, pp. 143-171.

20 X. H. Mao, R. Jiang, W. Xiao and J. G. Yu, J. Hazard. Mater., 2015, 285, 419-435.

21 B. Sarkar, M. Megharaj, Y. F. Xi, G. S. R. Krishnamurti and R. Naidu, J. Hazard. Mater., 2010, 184, 448-456.

22 B. Karimi, P. A. Maron, N. C. P. Boure, N. Bernard, D. Gilbert and L. Ranjard, Environ. Chem. Lett., 2017, 1-17.

23 M. L. Banks, A. C. Kennedy, R. J. Kremer and F. Eivazi, Appl. Soil Ecol., 2014, 74, 12-20.

24 X. D. Cui, Y. J. Wang, K. Hockmann and D. M. Zhou, Environ. Pollut., 2015, 204, 133-140.

25 Z. Y. Hu, Z. H. Yang, C. K. Xu, S. Haneklaus, Z. H. Cao and E. Schnug, J. Plant Nutr. Soil Sci., 2002, 165, 249-254.

26 H. Mokbel, E. J. Al Dine, A. Elmoll, C. Liaud and M. Millet, Environ. Sci. Pollut. Res., 2016, 23, 8053-8063.

27 Y. N. Zhang, X. L. Yang, C. G. Gu, F. Wang, Y. R. Bian, Y. Song, D. Z. Wang and X. Jiang, Sci. Total Environ., 2016, 569, 997-1003.

28 J. G. Caporaso, J. Kuczynski, J. Stombaugh, K. Bittinger, F. D. Bushman, E. K. Costello, N. Fierer, A. G. Peña, J. K. Goodrich, J. I. Gordon, G. A. Huttley, S. T. Kelley, D. Knights, J. E. Koenig, R. E. Ley, C. A. Lozupone, 
D. McDonald, B. D. Muegge, M. Pirrung, J. Reeder, J. R. Sevinsky, P. J. Turnbaugh, W. A. Walters, J. Widmann, T. Yatsunenko, J. Zaneveld and R. Knight, Nat. Methods, 2010, 7, 335-336.

29 R. C. Edgar, Nat. Methods, 2013, 10, 996-998.

30 K. R. Amato, C. J. Yeoman, A. Kent, N. Righini, F. Carbonero, A. Estrada, H. R. Gaskins, R. M. Stumpf, S. Yildirim, M. Torralba, M. Gillis, B. A. Wilson, K. E. Nelson, B. A. White and S. R. Leigh, ISME J., 2013, 7, 1344-1353.

31 P. D. Schloss, S. L. Westcott, T. Ryabin, J. R. Hall, M. Hartmann, E. B. Hollister, R. A. Lesniewski, B. B. Oakley, D. H. Parks, C. J. Robinson, J. W. Sahl, B. Stres, G. G. Thallinger, D. J. V. Horn and C. F. Weber, Appl. Environ. Microbiol., 2009, 75, 7537-7541.

32 W. H. Luo, K. Sasaki and T. Hirajima, Colloids Surf., A, 2015, 481, 616-625.

33 S. Khan, M. Waqas, F. H. Ding, I. Shamshad, H. P. H. Arp and G. Li, J. Hazard. Mater., 2015, 300, 243-253.

34 W. J. Tian, J. Zhao, Y. H. Zhou, K. L. Qiao, X. Jin and Q. Liu, Ecotoxicol. Environ. Saf., 2017, 135, 158-164.

35 M. Keshavarzifard, M. P. Zakaria and R. Sharifi, Arch. Environ. Contam. Toxicol., 2017, 1-14.

36 M. X. Guo, Z. Q. Gong, X. J. Li, G. Allinson, J. Rookes and D. Cahill, Ecotoxicol. Environ. Saf., 2017, 140, 191-197.

37 B. L. Chen, L. Z. Zhu, J. X. Zhu and B. S. Xing, Environ. Sci. Technol., 2005, 39, 6093-6100.

38 S. Zhao, G. Huang, C. J. An, J. Wei and Y. Yao, J. Hazard. Mater., 2015, 286, 144-151.

39 B. S. Griffiths and L. Philippot, FEMS Microbiol. Rev., 2013, 37, 112-129.

40 S. Gul, J. K. Whalen, B. W. Thomas, V. Sachdeva and H. Deng, Agric., Ecosyst. Environ., 2015, 206, 46-59.

41 K. G. V. Anand, D. Kubavam, K. Trivedi, P. K. Agarwal, C. Wheeler and A. Ghosh, Eur. J. Soil Biol., 2015, 69, 57-65.
42 Y. C. Li, Y. F. Li, S. X. Chang, X. Liang, H. Qin, J. H. Chen and Q. F. Xu, Soil Biol. Biochem., 2017, 107, 19-31.

43 Y. T. Lin, W. B. Whitman, D. C. Coleman, S. H. Jien and C. Y. Chiu, Appl. Soil Ecol., 2017, 112, 28-33.

44 G. D. Ren, Y. Teng, W. J. Ren, S. X. Dai and Z. G. Li, Pyrene dissipation potential varies with soil type and associated bacterial community changes, Soil Biol. Biochem., 2016, 103, 71-85.

45 A. Dell'Anno, F. Beolchini, L. Rocchetti, G. M. Luna and R. Danovaro, Environ. Pollut., 2012, 167, 85-92.

46 C. Anyika, Z. A. Majid, Z. Ibrahim, M. P. Zakaria and A. Yahya, Environ. Sci. Pollut. Res., 2015, 22, 3314-3341.

47 P. Isaac, F. L. Martínez, N. Bourguignon, L. A. Sánchez and M. A. Ferrero, Int. Biodeterior. Biodegrad., 2015, 101, 23-31.

48 M. Korlević, J. Zucko, M. N. Dragić, M. Blažina, E. Pustijanac, T. V. Zeljko, R. Gacesa, D. Baranasic, A. Starcevic, J. Diminic, P. F. Long, J. Cullum, D. Hranueli and S. Orlić, Syst. Appl. Microbiol., 2015, 38, 189-197.

49 N. Xia, X. H. Xia, T. Liu, L. J. Hu, B. T. Zhu, X. T. Zhang and J. W. Dong, J. Soils Sediments, 2014, 14, 1894-1904.

50 J. Keshri, A. Mishra and B. Jha, Microbiol. Res., 2013, 168, 165-173.

51 K. Zhalnina, R. Dias, P. D. de Quadros, A. Davis-Richardson, F. A. O. Camargo, I. M. Clark, S. P. McGrath, P. R. Hirsch and E. W. Triplett, Microb. Ecol., 2015, 69, 395-406.

52 F. M. Nakamura, M. G. Germano and S. M. Tsai, Diversity, 2014, 6, 339-353.

53 J. Tian, Y. L. Lou, Y. Gao, H. J. Fang, S. T. Liu, M. G. Xu, E. Blagodatskaya and Y. Kuzyakov, Biol. Fertil. Soils, 2017, 1-10.

54 N. Kennedy, E. Brodie, J. Connolly and N. Clipson, Environ. Microbiol., 2004, 6, 1070-1080.

55 Y. C. Wu, J. Zeng, Q. H. Zhu, Z. F. Zhang and X. G. Lin, Sci. Rep., 2017, 7, 40093. 